ADLFI. Archéologie de la France -

INFORMATIONS

Informations

une revue Gallia

Provence-Alpes-Côte d'Azur | 2007

\title{
La Tour-sur-Tinée
}

\section{Romuald Mercurin}

\section{OpenEdition \\ Journals}

Édition électronique

URL : http://journals.openedition.org/adlfi/6642

ISSN : 2114-0502

Éditeur

Ministère de la culture

Référence électronique

Romuald Mercurin, "La Tour-sur-Tinée », ADLFI. Archéologie de la France - Informations [En ligne], Provence-Alpes-Côte d'Azur, mis en ligne le 01 mars 2007, consulté le 03 mai 2019. URL : http:// journals.openedition.org/adlfi/6642

Ce document a été généré automatiquement le 3 mai 2019.

(c) Ministère de la Culture et de la Communication, CNRS 


\title{
La Tour-sur-Tinée
}

\author{
Romuald Mercurin
}

Identifiant de l'opération archéologique : 7963

Date de l'opération : 2006 - 2007 (PI)

Inventeur(s) : Mercurin Romuald (BEN)

1 La révision de l'inventaire archéologique de la commune de La Tour-sur-Tinée a été poursuivie en 2007 dans les mêmes conditions que l'année précédente (BSR PACA, 2006 : 97-98). Près de trente sites ont fait l'objet d'une prospection sur le terrain. Parallèlement, a été poursuivie la recherche documentaire, avec notamment le dépouillement de plusieurs documents d'archives. Une masse relativement importante de données a donc été récoltée cette année. Leur traitement a été entamé mais devra se poursuivre au cours de l'année 2008.

2 Neuf nouveaux sites ont pour l'instant fait l'objet d'une fiche détaillée, montant à trentequatre le nombre total de sites ou indices de sites déjà inventoriés.

3 Les périodes de la Préhistoire et de la Protohistoire restent toujours non documentées sur le territoire de la commune.

\section{Période antique ou médiévale}

4 Trois des sites datés de la période antique et inscrits dans la base de données Patriarche ont été révisés : Le Renoou (anc. La Condamine), Le Villars et Rigagnon 1 (anc. L'Agadge). La présence exclusive, sur les trois sites, de fragments de tuiles plates à rebord remployés dans l'appareillage des murs de terrasses ou de structures plus récentes, empêche de confirmer une datation antique. Ces vestiges permettent cependant d'envisager une occupation des secteurs concernés antérieure aux Temps Modernes. Les trois indices de sites ont donc été attribués à la période antique ou médiévale, l'absence de fossiles 
directeurs clairement identifiables et/ou de structures associées ne permettant pas d'être plus précis.

\section{Période des Temps Modernes}

5 C'est à nouveau la période des Temps Modernes qui s'est révélé la plus prolixe, avec cinq nouveaux sites dont l'église paroissiale Saint-Martin, datée sur la base de critères stylistiques du début du XVI ${ }^{\mathrm{e}}$ s. L'édifice, classé aux Monuments historiques, reste cependant mal connu et mériterait une étude approfondie. La découverte d'une salle située sous la chapelle du Saint-Esprit (adjointe au corps principal auXVII ${ }^{\mathrm{s}} \mathrm{s}$.), à l'extérieur de l'église, permet d'envisager l'existence de souterrains sous la nef. À noter que la présence religieuse est attestée à La Tour dès le XII ${ }^{\mathrm{e}}$ s., ce qui pose la question d'un édifice plus ancien.

6 Trois sites d'habitats témoignent des différentes modalités d'occupation des sols et d'exploitation du terroir aux XVII ${ }^{e}$ s. et XVIII ${ }^{e}$ s. Les demeures de Lubac (1680) et du Collet des Padres illustrent un habitat dispersé voué à l'exploitation agropastorale des versants surplombant la Tinée. La présence, au Collet des Padres, de tessons de céramique pisane du début du XVII ${ }^{e}$ s. et de céramique d'Albisola du XVIII ${ }^{e}$ s., pris dans la maçonnerie d'une des pièces, offrent d'intéressants éléments de datation. L'habitat groupé est représenté par le hameau de Ripert, dont l'existence au XVIII ${ }^{\mathrm{e}}$ s. est assurée par sa mention sur la carte de F. Prato.

7 Enfin, le moulin à huile Audisio ne peut être daté avec certitude de la période des Temps Modernes mais pourrait être antérieur à la Révolution selon Luc Thévenon (1994).

\section{Temps modernes ou époque contemporaine}

8 Aucun site n'a été attribué avec certitude à l'époque contemporaine, mais le complexe agropastoral (habitat, bergerie, grange, bassin) de l'Ubac du Chianet peut être rattaché soit à cette période, soit à la période des Temps Modernes.

9 L'année 2008 sera entièrement consacrée au travail de post-prospection avec la réalisation des fiches concernant les autres sites prospectés cette année (dont plusieurs chapelles et les inscriptions militaires gravées de la route des Granges de la Brasque) et le traitement des sources écrites.

MERCURIN Romuald

\section{INDEX}

Index chronologique : Antiquité romaine, ép. contemporaine, Moyen Âge*, Temps Modernes, XIIe siècle apr. J.-C., XVIe siècle apr. J.-C., XVIIe siècle apr. J.-C., XVIIIe siècle apr. J.-C.

operation Prospection inventaire (PI)

Index géographique : Provence-Alpes-Côte d'Azur, Alpes-Maritimes (06), Tour 
AUTEURS

ROMUALD MERCURIN

BEN 